1 Universidade Federal do Rio Grande do Norte (UFRN), Escola de Saúde Natal (RN), Brasil. lygia.melo@yahoo.com.br

2 Universidade Estadual da Paraíba (UEPB), Programa de Pós-Graduação em Saúde Pública e Departamento de Enfermagem - Campina Grande (PB), Brasil. cmartiniano@ibest.com.br

3 Universidade Federal do Rio Grande do Norte (UFRN), Escola de Saúde - Natal (RN), Brasil. jaciguim@yahoo.com.br

4 Universidade Federal do Rio Grande do Norte (UFRN), Escola de Saúde Natal (RN), Brasil.

marizebs@gmail.com

5 Universidade Federal do Rio Grande do Norte (UFRN),

Programa de Pós-Graduação em Saúde Coletiva e

Departamento de Saúde

Coletiva - Natal (RN), Brasil.

paulodemedeirosrocha@gmail.com

\section{Análises das diretrizes para o apoio institucional das gestões da Atenção Básica das capitais brasileiras}

\author{
Analysis of the guidelines for the institutional support of \\ managements of Primary Care of the Brazilian capitals \\ Lygia Maria de Figueiredo Melo', Claudia Santos Martiniano ${ }^{\mathbf{2}}$, Jacileide Guimarães ${ }^{\mathbf{3}}$, Marize \\ Barros de Souza ${ }^{\mathbf{4}}$, Paulo de Medeiros Rocha ${ }^{5}$
}

RESUMO Objetivou-se investigar os limites e as potencialidades das diretrizes gerais das gestões da Atenção Básica das capitais brasileiras para o apoio institucional. O estudo é descritivo, exploratório, qualitativo, realizado de fevereiro a outubro de 2014, a partir do módulo IV do Programa Nacional de Melhoria do Acesso e da Qualidade da Atenção Básica. Incluíram-se 22 formulários de gestão de capitais brasileiras analisados com o software Atlas ti.7.1 e análise de conteúdo. Nas capitais brasileiras, as condições de gerir os processos para a institucionalização do apoio não é uma realidade predominante. Conclui-se que essas gestões precisam ser apoiadas na condução desses processos.

PALAVRAS-CHAVE Gestão em saúde; Política de saúde; Avaliação em saúde; Atenção Primária à Saúde.

ABSTRACT This study aimed to investigate the limits and potential of the general guidelines of the managements of Primary Care of the Brazilian capitals for the institutional support. The study is exploratory, descriptive, qualitative, conducted from February to October 2014, from the Module IV of the National Program for Access and Quality Improvement in Primary Care. Were included 22 Brazilian capital management forms analyzed with the Atlas ti.7.1 software and content analysis. In the Brazilian capitals, the conditions to manage the processes for the institutionalization of support is not a mainstream reality. We conclude that these efforts need to be supported in conducting these processes.

KEYWORDS Health management; Health policy; Health evaluation; Primary Health Care. 


\section{Introdução}

No cenário internacional, é crescente a percepção, pelas agências e pelos governos, de que o enfrentamento das dificuldades dos sistemas de saúde passa pelo fortalecimento da Atenção Primária à Saúde (APS) e pelo seu reconhecimento, como estratégia para viabilizar o ordenamento e romper com a fragmentação existente (OMS, 2008). A APS é concebida como o serviço de primeiro contato dos usuários com o sistema de saúde, cuja função é regular o acesso e coordenar o cuidado em toda a rede de atenção (STARFIELD, 2002; OMS, 2008).

Em consonância com o debate internacional sobre as necessidades de reforma nos sistemas de saúde, proposta pela OMS, e, ainda, com o enfrentamento dos desafios do Sistema Único de Saúde (SUS) e o reconhecimento da importância da Atenção Básica (AB) como ordenadora do cuidado, em 2011, o Ministério da Saúde (MS), através da Portaria ${ }^{0}$ 1.654, de 19 de julho de 2011, institui o Programa Nacional de Melhoria do Acesso e da Qualidade da Atenção Básica (PMAQ-AB). Para a gestão federal, incorporar o PMAQ-AB às diretrizes do MS é reconhecer o seu caráter inovador, por associar, pela primeira vez, a transferência de recursos à implantação e ao alcance de padrões de acesso e de qualidade pelas Equipes de Atenção Básica (EqAB) (BRASIL, 2012B).

A operacionalização do PMAQ-AB se dá em quatro fases contínuas (BRASIL, 2012B), a saber: fase 1) adesão e contratualização: gestão e equipes aderem ao programa com a contratualização de compromissos e indicadores; fase 2) desenvolvimento: inclui processos de autoavaliação, monitoramento dos indicadores contratualizados e do apoio institucional às EqAB e ações de educação permanente; fase 3) avaliação externa: engloba um conjunto de ações direcionadas para a certificação das condições de acesso e de qualidade da atenção ofertada pelas EqAB participantes do PMAQ-AB; e fase 4) recontratualização: com base na avaliação de desempenho de cada equipe, uma nova contratualização de indicadores e compromissos deverá ser realizada, completando o ciclo de qualidade.

Portanto, a aposta da gestão federal é que o PMAQ-AB institua um ciclo virtuoso de indução de boas práticas, tanto de gestores quanto de profissionais, num movimento contínuo de institucionalização da avaliação na AB (BRASIL, 2012B).

Para Contandriopoulos (2006), a avaliação tem um caráter estratégico, já que consiste em uma atividade voltada para a ação, considerada como um dos caminhos para o enfrentamento da crise dos sistemas de saúde. Para tanto, faz-se necessário que a sua institucionalização ocorra em todos os níveis do sistema, provocando uma cultura de avaliação que possibilite que as decisões sejam tomadas a partir de evidências comprovadas. Nesse contexto, é imprescindível também avaliar a avaliação, pondo em questão a capacidade dos modelos de avaliação existentes no SUS de gerar informações e julgamentos necessários, contribuindo com as instâncias decisórias para melhorar o seu desempenho.

Trata-se de uma provocação para a urgência de se incorporar, nos campos da avaliação, da gestão e do cuidado, a institucionalização de práticas que não percam os processos instituintes.

Ao se evidenciar a importância de um ambiente organizacional democrático para a construção de processos participativos, ganha pertinência o debate realizado por Campos $(1998,2000,2003,2005)$ sobre os modelos de gestão adotados no SUS. O autor contribui com o campo da saúde com a crítica à racionalidade gerencial predominante nas escolas de administração que seguem o paradigma funcionalista e que se refletem no âmbito dos estudos e das premissas da gestão no setor. Também aponta os reflexos desses modelos de gestão no mundo do trabalho, destacando, em particular, como 
a racionalidade científica afeta a cotidianidade das práticas de gestão e de cuidado no SUS, ainda que a sua construção esteja alicerçada em um projeto democratizante para todos os níveis da gestão.

Conforme Silveira (2005), visões diferentes do funcionalismo para análise das organizações possibilitaram diversos estudos e abordagens alicerçadas nas ideias de Michel Foucault, a exemplo da análise de saber-poder e da compreensão de que as organizações, ao mesmo tempo, refletem e reproduzem o poder disciplinar.

Salienta-se, ainda, a contribuição da análise institucional (BAREMBLITT, 2002, P. 137), que destaca as simultâneas diferenciação e complementariedade entre organizações e instituições, sendo que, enquanto organizações, caracterizam "as formas materiais nas quais as instituições se realizam ou 'encarnam' [...]”. As instituições são compostas pela linguagem, pelas relações interpessoais, pela divisão social do trabalho, entre outros códigos fundantes das sociedades humanas. A instituição, portanto, compreende o instituinte (que a engendra), o instituído (resultado) e a institucionalização (processo).

A essa mesma perspectiva institucionalista, Campos (2000) acrescenta que as instituições ganham vida através de seus objetivos organizacionais, que, para o autor, dizem respeito ao seu duplo objetivo, qual seja: o de produzir bens ou serviços de interesses sociais e o de assegurar a sobrevivência da própria organização e dos sujeitos que dela fazem parte. $\mathrm{O}$ reconhecimento dessa duplicidade de objetivos da instituição torna-se essencial, ainda na perspectiva do autor, para se pensar em novas formas de gerir coletivos organizados para a produção da saúde.

A partir da crítica à racionalidade gerencial hegemônica, de reflexões teóricas e do acúmulo de experiências práticas no campo da saúde, Campos (2000) sistematiza um método de apoio para cogovernar as organizações de saúde, considerando que formas burocratizadas de gestão produzem empobrecimento subjetivo e social do trabalho. O método se volta para análise e a cogestão de coletivos (Método da Roda/ Apoio Paidéia/Apoio Institucional), que, fundamentado em um conjunto de conceitos operativos advindos do campo da política, do planejamento, da análise institucional e da pedagogia, concebe a cogestão como movimento político de desconcentração de poder e, portanto, potencializador da democracia institucional e da autonomia dos sujeitos.

Na perspectiva de Campos (2003, P. 87), o apoio institucional pressupõe

[...] uma pressão de fora, implica trazer algo externo ao grupo que opera os processos de trabalho ou que recebem bens e serviços. Quem apoia sustenta e empurra ao outro [...].

Como postura metodológica, o apoio busca reformular os tradicionais mecanismos de gestão, alterando complementarmente as formas de se realizar coordenação, planejamento, supervisão e avaliação do trabalho em equipe.

Em 2003, o apoio é incorporado ao discurso oficial do MS, iniciando um processo de formulação e implantação do apoio institucional, com produção sistemática de textos e documentos (PEREIRA JÚNIOR; CAMPOS, 2014). Portanto, é pelo potencial do apoio de estabelecer processos de mudança em coletivos e em instituições, através da adoção de práticas institucionais democráticas e estímulo à autonomia dos sujeitos, que se evidencia a importância fundamental da função apoio no cenário da $\mathrm{AB}$.

Diante da urgência para a implementação de modelos de gestão participativa que contribuam para que o SUS se afirme como política pública e de qualidade, o MS reconhece a importância estratégica da função apoio como dispositivo de intervenção para a operacionalização da política nacional de 
saúde e fortalecimento da $\mathrm{AB}$. Na esteira da institucionalização de novos modos de gerir coletivos, o governo incorpora o apoio institucional a vários documentos e publicações: a Política Nacional de Humanização (PNH), o Caderno HumanizaSUS, o Documento Base para gestores e trabalhadores do SUS, a Política Nacional de Atenção Básica (PNAB), o instrumento de Autoavaliação para a Melhoria do Acesso e da Qualidade da Atenção Básica (AMAQ) e o Documento Síntese para Avaliação Externa do PMAQ-AB.

Ressalta-se que, no instrumento da $A M A Q-A B$, realizada pelas EqAB, o apoio institucional foi uma das subdimensões avaliadas (BRASIL, 2012A). Com base nas competências da gestão e da equipe, foram estabelecidas unidades de análise para a autoavaliação agrupando-se padrões de qualidade definidos a priori por guardarem relação direta com o fazer da gestão, da coordenação e das equipes. Ao mesmo tempo, os padrões definem o que se espera em termos de qualidade para a $A B$ no SUS.

No momento em que as reformas no campo da gestão e do cuidado se colocam como fundamentais para o fortalecimento da APS/AB em todos os sistemas de saúde e, particularmente, para o SUS, acredita-se ser relevante o esforço empreendido com essa pesquisa no sentido de contribuir para a reflexão sobre os processos de institucionalização da avaliação na $\mathrm{AB}$, pondo em análise, inclusive, as possibilidades de o instrumento da avaliação externa captar as dimensões que se propõe a avaliar com relação ao apoio institucional.

Nessa investigação, parte-se do pressuposto de que o exercício da função apoio implica a cogestão de coletivos através da utilização de ferramentas de negociação, mediação de conflitos, composição articulada de projetos, plano e oferta de uma formação ampliada para os sujeitos envolvidos, bem como o apoio para as equipes para lidar com as demandas provenientes da cotidianidade da AB (CAMPOS; CUNHA; FIGUEIREDO, 2013).

Assim, a hipótese levantada é a de que, por ser o apoio uma função gerencial fundamental para instaurar processos de mudanças nas organizações e coletivos, as diretrizes gerais para o apoio institucional propostas pelas gestões de $\mathrm{AB}$ das capitais brasileiras devem ser promotoras de democracia institucional e autonomia dos sujeitos.

O objetivo desta pesquisa é investigar os limites e as potencialidades das diretrizes gerais das gestões da $\mathrm{AB}$ das capitais brasileiras para o apoio institucional como dispositivo para estimular a democracia institucional e a autonomia dos sujeitos.

\section{Metodologia}

Estudo descritivo, exploratório, de abordagem qualitativa que teve como cenário a $\mathrm{AB}$, em particular, o momento atual em que o governo federal lança o PMAQ-AB com o objetivo de incentivar os gestores e as EqAB à melhoria do acesso e do padrão de qualidade da assistência ofertada aos usuários do SUS nesses serviços. No contexto do PMAQ-AB, a pesquisa se volta, especificamente, para a fase 3 do programa (avaliação externa) nas capitais brasileiras (equipes e gestões), na qual foram coletadas informações que deram origem à base de dados do PMAQ-AB/Departamento de Atenção Básica (DAB)/MS.

No conjunto dos municípios submetidos à avaliação externa pela pesquisa PMAQ$\mathrm{AB}$, foi feito um recorte intencional, de modo a proceder à análise da oferta do apoio institucional nas capitais brasileiras. Essa opção deu-se em virtude de que as capitais brasileiras, potencialmente, contam com uma maior estrutura física, organizacional e de recursos humanos para uma maior oferta de serviços de saúde e do apoio institucional às EqAB.

O grupo amostral foi composto pelos respondentes do módulo IV, que correspondeu 
aos gestores da $\mathrm{AB}$ das capitais brasileiras. Do universo das 27 capitais brasileiras, quatro não fizeram adesão ao PMAQ-AB, e, em uma das capitais, o gestor da $A B$ não respondeu às questões na plataforma virtual (módulo IV), tendo o município sido excluído do estudo. Desse modo, a amostra foi composta por 22 gestores.

A coleta de dados foi realizada no período de fevereiro a outubro de 2014 por meio do instrumento virtual módulo IV gestor. Nesse instrumento, as informações foram digitadas livremente em um campo específico por cada um dos gestores e alimentadas na plataforma virtual do Sistema de Gestão de Programas do Departamento de Atenção Básica (SIGDAB).

A análise dos dados foi concomitante à coleta. Para a organização e o arquivamento dos dados, utilizou-se como ferramenta o computador, por meio do software para análise de dados qualitativos Atlas ti.7.1, sob o número de licença 78504-E7359-3117E-8EB11-0013R.

Como metodologia de interpretação, empregou-se a análise de conteúdo temática (BARDIN, 2011). Para tanto, procedeu-se às seguintes etapas: pré-análise, em que, a partir das regras da exaustividade, representatividade e pertinência, iniciou-se a leitura flutuante do material, seguindo-se com a demarcação do que seria analisado para constituir o corpus. Seguiu-se a fase exploratória em que se codificaram as categorias, identificando-se as unidades de registro. Nessa etapa, as diretrizes para o apoio propostas por cada gestor foram analisadas linha a linha de forma a se descobrir os núcleos de sentido (tema) que permitissem identificar motivações, valores e tendências das gestões da $\mathrm{AB}$ no que diz respeito às diretrizes institucionais para o apoio. Nesse processo, foram identificadas e agrupadas três categorias e dez subcategorias (figura 1).

Figura 1. Categorias e subcategorias analisadas

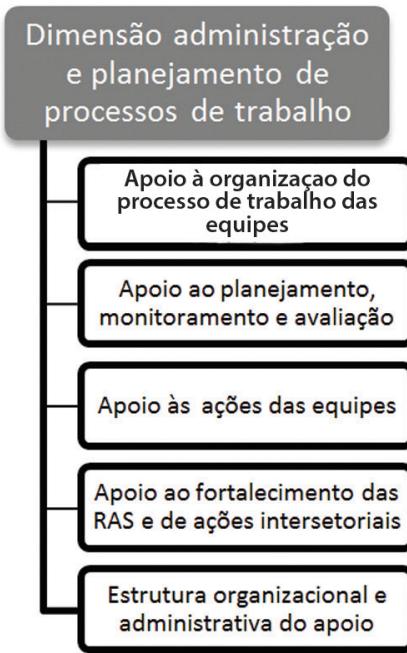

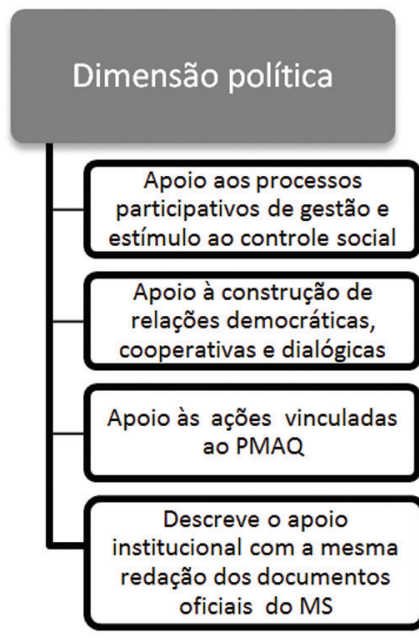

Fonte: Elaboração própria.

Por fim, passou-se para a última fase, referente ao tratamento dos resultados, na qual, norteados pelos fundamentos do apoio Paidéia, proposto por Campos (2000), e por documentos do MS que definem os padrões de qualidade para o apoio institucional na $A B$, as diretrizes gerais das gestões da $\mathrm{AB}$ das capitais brasileiras propostas pelos gestores no 
módulo IV foram interpretadas realizando-se inferências sobre os resultados encontrados.

\section{Aspectos éticos}

O projeto multicêntrico Avaliação da Atenção Básica no Brasil: Estudos Multicêntricos Integrados sobre Acesso, Qualidade e Satisfação dos Usuários foi aprovado pelo Comitê de Ética em Pesquisa da Universidade Federal do Rio Grande do Sul, sob o número 21.904, em 13/03/2012, e está em consonância com a Resolução no. 196/96 do Conselho Nacional de Saúde (CNS). Com o intuito de preservar o anonimato, os gestores da $\mathrm{AB}$ foram identificados com codinomes (G1 a G22), de acordo com o número correspondente à sequência ordinária em que os dados foram inseridos no programa Atlas ti.

\section{Resultados e discussão}

Os municípios são locus privilegiados com alta capilaridade e com alto potencial na implantação de processos de alteração de modelos de gestão e atenção no SUS, sustentados pelo princípio da cogestão. Assim, é fundamental pôr em evidência o potencial das diretrizes propostas pelas gestões da $\mathrm{AB}$ para essas transformações, e, ainda, as aproximações ou o distanciamento para construção de uma democracia institucional e autonomia dos sujeitos.

Observou-se que somente em cinco capitais as gestões (G1, G3, G14, G16, G21) assumiram uma compreensão mais coerente com os pressupostos do apoio institucional, contemplando, além da dimensão administração e planejamento de processos de trabalho, as dimensões política e pedagógica do apoio.

\section{Dimensão: administração e planeja- mento de processos de trabalho}

Também foi evidenciado que a maioria das gestões concentraram as suas diretrizes na 'dimensão administração e planejamento de processos de trabalho', principalmente no que diz respeito ao 'apoio ao planejamento, monitoramento e avaliação; ao fortalecimento das Redes de Atenção à Saúde (RAS) e ações intersetoriais no município e à organização do processo de trabalho das equipes'.

No que se refere, especificamente, ao apoio ao planejamento, monitoramento e avaliação, observou-se, entre as gestões, a ênfase dada por G3 a esses processos quando várias de suas diretrizes apontam para a necessidade de

'monitorar', acompanhar e avaliar as equipes das UBSF [Unidades Básicas de Saúde da Família] de acordo com as diretrizes da SMS; 'planejar, coordenar, supervisionar e avaliar' as ações de prevenção, promoção e atenção à saúde das UBSF da área de abrangência do Distrito; realizar 'diagnóstico situacional' em conjunto com as UBSF; participar da elaboração de 'planejamento para a melhoria' da qualidade do trabalho no Distrito e nas UBSF. (G3).

Corroborando os processos de planejamento, monitoramento e avaliação, têm-se, na mesma direção, algumas das diretrizes de G3, G6, G10, G12, G14 e G 21: "Utilizar ferramentas de planejamento e da gestão da clínica" (G3); "apoiar o planejamento local 'e monitoramento de indicadores' integrados aos pactos da SMS a exemplo do PMAQ", "apoio ao 'monitoramento do acesso' pelas EqSF [Equipes de Saúde da Família]” (G6); "favorecer a 'identificação e análise de problemas" (G10); "realização do "monitoramento e avaliação" (G12); "apoiar as EqAB e apoio matricial no "planejamento, monitoramento e avaliação dos indicadores de desempenho e resultados' e apoiar o processo de 'autoavaliação’ das equipes” (G14); “avaliação’ dos processos" (G21).

O entendimento da importância do apoio no fortalecimento das RAS e ações intersetoriais, como forma de articular os diversos 
níveis de atenção/gestão e de promover maior integração, foi algo referido, principalmente, por G1, como exemplificado abaixo, embora esteja presente, também, em algumas das diretrizes propostas por G2, G3, G6, G16, G18 e G21.

Apoiar matricialmente (Núcleos de Apoio à Saúde da Família - Nasf); 'desenvolver parceria' com [Instituição A] para disponibilizar ferramenta online no site da SMS disponível aos apoiadores e implantação gradativa 'por níveis de gestão'; editar o caderno da coletânea de instrumentos norteadores da EqSF com a temática para 'propiciar integração com serviços estaduais e municipais'; propor prática do apoio institucional às equipes da EqSF, 'integrando diferentes níveis de gestão'. (G1).

Em se tratando das diretrizes voltadas ao apoio à organização do processo de trabalho das equipes, percebeu-se um movimento de algumas gestões (G1, G6 e G18) em apoiar a organização do trabalho a partir da realidade dos profissionais e da demanda, utilizando antigas e novas ferramentas de gestão, alicerçando o enfrentamento de problemas numa construção coletiva.

Estruturar 'instrumento inovador' para processo de trabalho/gestão de equipes com eixos norteadores e 'análise observacional' e resolução de problemas; desenvolver parceria com o [Instituição B] de ferramenta online no site da [Instituição C] disponível aos apoiadores e ampliação gradativa por níveis de gestão; 'manejar demandas' advindas da prática (percebidas pelo apoiador, as que surgem da unidade, do controle social e ouvidoria). (G1).

Também se observa que alguns gestores (G5, G7, G19, G22) utilizaram o espaço do módulo IV - espaço destinado à descrição das diretrizes gerais para o apoio no município - para, exclusivamente, dissertarem sobre o modo como este se encontrava estruturado na Secretaria Municipal de Saúde.
Temos, dentro de cada unidade de saúde, um profissional que é o apoiador direto das equipes. Em cada distrito sanitário, temos uma equipe composta por coordenador de informação, coordenador de assistência, coordenador de vigilância à saúde, além do supervisor. Dentro do centro de informação em saúde temos apoiadores em todas as áreas estratégicas da SMS [Secretaria Municipal de Saúde]. (G5).

Ainda com relação à estrutura, dois gestores (G4 e G9) explicitam no módulo IV que ainda não implantaram o apoio institucional para as EqAB no município, embora haja um movimento nesse sentido.

Apesar de diversas iniciativas e planejamento de ações neste sentido, a Secretaria 'ainda não está realizando' o apoio institucional formalizado. (G4).

O apoio institucional está 'em fase de discussão' com o grupo de apoiadores, onde será definido, na oficina, o método de apoio e os resultados esperados. A proposta é que sejam formadas 9 equipes de apoio para as 51 equipes de saúde da família, e 07 equipes do Pacs [Programa de Agentes Comunitários de Saúde], sendo 03 apoiadores para cada 06 equipes. (G9).

Analisar as diretrizes gerais do apoio institucional das gestões de $\mathrm{AB}$ das capitais brasileiras significa estar diante das intencionalidades, dos caminhos traçados por gestores e equipes de gestão desses municípios no que se refere ao apoio institucional. No entanto, o que se constatou é que, no que diz respeito às diretrizes voltadas para a dimensão 'administração e planejamento de processos de trabalho', a perspectiva de construção coletiva foi pouco evidenciada na redação das diretrizes institucionais para o apoio na maioria das capitais brasileiras. Para os processos de planejamento, monitoramento e avaliação, por exemplo, nenhuma gestão utilizou o termo 'usuário', levando 
a pensar que o apoio tem sido pensado, em muitos casos, sem a participação efetiva da população, o que pode significar que, para as gestões, esses processos são destinados apenas aos gestores e profissionais das equipes.

A não participação do usuário foi fato também evidenciado por Feuerwerker (2014), quando afirma que, muitas vezes, nas experiências em Educação Permanente em Saúde (EPS), percebe-se a evidente ausência do usuário e a ênfase dada de forma majoritária na relação gestão-trabalhadores.

Campos (2000) salienta que a forma como as organizações ganham vida é através de seus objetivos organizacionais, que, por sua vez, estão relacionados à produção de bens ou serviços de interesses sociais e para assegurar a sobrevivência da própria organização e dos sujeitos que dela fazem parte.

No instrumento de autoavaliação das equipes (BRASIL, 2012B), é clara a opção de um modelo participativo de avaliação, de modo que o julgamento das ações das gestões e das equipes fosse realizado com envolvimento das EqAB, gestão e usuários, independentemente do nível de formação dos envolvidos. Essa perspectiva contribui para refletir sobre a realidade local, favorece a construção da democracia, em virtude da desconcentração de poder na equipe, do compartilhamento de responsabilidades e da apropriação por todos do processo de trabalho e dos indicadores de saúde pactuados.

$O$ instrumento da AMAQ também reforçava a ênfase em processos democráticos de gestão e de atenção, uma vez que

[...] Espera-se que as ações de monitoramento e avaliação tenham caráter formativo, pedagógico e reorientador das políticas e práticas, numa abordagem de informação para a ação, e sejam incorporadas no conjunto das atividades dos gestores e das equipes. (BRASIL, 2012A, P. 16).

Como nos apresenta Baremblitt (2002), as instituições não possuem vida concreta sem as organizações. Por sua vez, as organizações não possuem sentido, objetivo e direção sem as instituições. É nesse movimento de correlações de forças entre o instituído, o instituinte e os processos que nelas ocorrem que a instituição herda, fortemente, os traços daquilo que a materializa. Dito de outra forma, incorpora métodos e técnicas organizacionais herdados da lógica de Taylor e Fayol, que caracteriza um modelo fragmentado e hierarquizado de organizar e gerir os processos de trabalho.

Esse alerta é realizado por Pereira Júnior e Campos (2014) no tocante ao planejamento, à avaliação e ao monitoramento, pois, apesar de os reconhecerem como principais tecnologias de gestão do apoio, salientam que, muitas vezes, essas ferramentas são trabalhadas e incorporadas na prática por meio de concepções diferenciadas.

A todo o momento, nas instituições, fazem-se opções, sejam elas veladas ou explícitas. Nesse sentido, Lourau (2004) e Foucault (2009) ajudam a compreender esse cenário quando afirmam que a instituição não é apenas o conjunto de normas e leis, mas, também, a forma como os sujeitos se relacionam e se colocam com relação a essa mesma instituição, que se encontra permeada por relações de saber e poder, práticas discursivas e não discursivas.

O apoio exige deslocamentos e reposicionamentos constantes para que se alcancem novas reconfigurações de processos que, ao longo do tempo, foram sendo instituídos no cotidiano. Esses movimentos/rearranjos, nas visões de Paulon, Pasche e Righi (2014), geram a necessidade de enfrentamento de conflitos e de capacidade de lidar com diferentes graus de sofrimentos, mas são essenciais para que se possa, de fato, disparar processos de mudança em coletivos, capacitando as equipes e organizações a produzir mais e melhor saúde.

A relevância dada pelos autores a esses acontecimentos faz com que afirmem que 
a função apoio se exerce menos para a obtenção dos fins da organização (metas e resultados) e mais para a produção de reposicionamentos no trabalho. (PAULON; PASCHE; RIGHI, 2014, P. 818).

No entanto, os autores ressaltam que tal afirmativa não significa negar o compromisso do apoio com a tríplice finalidade dos serviços de saúde (a produção de saúde, a realização profissional e pessoal dos trabalhadores e a sua própria reprodução), mas chamam a atenção para o fato de que, ao não se considerarem as demandas advindas de interesses dos trabalhadores e usuários na construção de metas institucionais,

corre-se o risco de as planificações virarem tão somente documentos destinados às 'gavetas' ou a alguma 'nuvem virtual', [grifo dos autores] se quisermos modernizar o ato de escanteá-los. (PAULON; PASCHE; RIGHI, 2014, P. 818).

\section{Dimensão política}

A categoria 'dimensão política' encontra-se alicerçada no potencial do apoio em instaurar processos de mudança em coletivos e em instituições através da adoção de práticas institucionais democráticas que alterariam as relações de poder. Assim, nessa categoria, agrupamos as diretrizes institucionais na perspectiva de conseguir apreender os movimentos de concentração ou desconcentração de poder.

A partir do material empírico analisado, surgiram quatro subcategorias: 'descrição do apoio institucional utilizando a mesma redação dos documentos oficiais do MS; apoio às ações vinculadas ao PMAQ-AB; apoio aos processos participativos de gestão e estímulo ao controle social e apoio à construção de relações democráticas, cooperativas e dialógicas'. Verificou-se que as gestões G5, G6, G7, G8, G12, G19, G20 não se referiram a essa categoria.
Observou-se que G17 e G20 preencheram o formulário virtual, não apontando diretrizes, mas, sim, definindo o apoio institucional, utilizando, para tanto, 'a mesma redação contida nos documentos oficiais do MS', como se observa no fragmento a seguir:

Realizar apoio junto aos serviços 'como um modo específico de fazer gestão junto a coletivos/equipes, reconhecendo a complexidade do trabalho coletivo e tomando os problemas concretos, desafios e tensões do cotidiano como matéria prima para seu trabalho, a fim de facilitar a conversão de situações paralisantes em situações produtivas'. (G20).

Outro conjunto de diretrizes que merece destaque diz respeito à subcategoria 'Apoio às ações vinculadas ao PMAQ-AB'. O apoio institucional às equipes é identificado pela PNAB como uma das competências das Secretarias Municipais de Saúde no processo de implantação, acompanhamento e qualificação da $\mathrm{AB}$ e, também, da ampliação e consolidação das EqSF. Desse modo, o apoio é incorporado tanto na AMAQ como no PMAQ-AB com foco na qualificação daquilo que é ofertado à população.

Compreende-se, portanto, que a centralidade do apoio institucional deva ser a mudança nas organizações (gestão e atenção). Desse modo, opera disparando processos de mudança e oferecendo suporte a coletivos e não especificamente a qualquer programa governamental, como é o caso do PMAQ-AB, como parece ser a compreensão de alguns gestores. Tal observação decorre do fato de que a redação de algumas diretrizes para o apoio institucional foi parcial ou totalmente atrelada a ele.

Estimular as equipes $P M A Q$ através de acréscimo salarial com os recursos a serem repassados pelo $P M A Q$; investir o recurso do PMAQ na infraestrutura das USFs [Unidades de Saúde da Família]; priorizar ações de educação permanente para as equipes PMAQ; reformar as salas de vacina com o 
primeiro repasse fundo a fundo do PMAQ; apoiar as equipes junto ao PMAQ. (G11).

Esse entendimento limitado da estratégia do apoio pode fazê-lo perder sua potência de ferramenta instituinte no momento que ele se institui numa dada realidade de forma acrítica, contribuindo, assim, não para mudança, mas para a estagnação institucional.

Para Feuerwerker (2014), é importante incorporar no discurso institucional a intencionalidade de mudanças de práticas e de reorientação do modelo de atenção, embora se admita que ainda sejam de pouca monta os volumes de recursos envolvidos para esse fim, o que faz a autora afirmar que o investimento na mudança é marginal.

Por outro lado, pode-se observar que algumas gestões construíram algumas de suas diretrizes respaldando-se em objetivos mais democráticos quando reconhecem a necessidade do apoio institucional ser voltado para o 'apoio aos processos participativos de gestão e estímulo ao controle social' (G1, G2, G3, G12 e G16). "Deliberar situações provenientes dos conselhos locais; manejar demandas percebidas pelo apoiador advindo do controle social e ouvidorias" (G1); "Desenvolver a gestão participativa no SUS no município com objetivo de fortalecer a gestão e o controle social do SUS" (G2).

É na dimensão de construção da democracia institucional que reside o caráter político da metodologia do apoio. Para Campos (2014), a potência do apoio se sustenta, fundamentalmente, na possibilidade de alterar as relações de poder, no sentido de aproximação e compreensão das formas como os indivíduos cotidianamente exercem, sublevam e resistem ao poder na micropolítica do cotidiano da gestão e da atenção.

O poder, como nos adverte Foucault (2009, P. 175), concebido não como uma coisa, mas como prática social construída historicamente, e que, como tal, nas instituições, se "corporifica em técnicas e se mune de instrumentos de intervenção material", produzindo discursos e práticas sociais, repressivos, resistentes ou dialógicos.

Portanto, há possibilidades, por meio do exercício da cogestão e da gestão participativa, de se caminhar na direção da construção de relações mais horizontalizas nas instituições, uma vez que esse elemento da metodologia do apoio possibilita a construção coletiva de contratos e compromissos entre os sujeitos envolvidos.

Ressalta-se que a forma como G12 propõe o estímulo à cogestão é através de 'oficinas, visitas e reuniões técnicas nas unidades de saúde da família, assessoria ao planejamento das equipes', o que, por si, não garante a criação de espaços de cogestão, pois o apoio só se estabelece na grupalização, que se traduz em rodas de conversa, discussões permanentes e horizontalizadas que possibilitem escuta qualificada das demandas advindas do cotidiano de práticas das equipes (PAULON; PASCHE; RIGHI, 2014).

Outro direcionamento dado às diretrizes de algumas gestões que apontam, do mesmo modo, para a desconcentração de poder foi o 'apoio à construção de relações democráticas, cooperativas e dialógicas', apontadas por G1, G3, G10, G12, G15 e G21. Parece claro para os gestores o entendimento de que o apoio tem como diretrizes a democratização institucional e a autonomia dos sujeitos. Essa autonomia é conquistada a partir do momento em que apoiador/apoiado se dilatam e permitem pôr em análise os saberes, os poderes e os fazeres presentes nas práticas e nas relações que se estabelecem na cotidianidade da AB.

Percebe-se a compreensão, por parte desses gestores, de que as instituições, além de produzirem serviços, produzem sujeitos e, portanto, subjetividades. "Mediar conflitos com implantação da psicologia organizacional” (G1); "Apoio aos profissionais no enfrentamento de conflito" (G12).

Desenvolver processos de reflexão e mudança das práticas a partir do fazer cotidiano das EqAB; potencializar os esforços e experiências vivenciadas 
pelas equipes, fortalecendo a responsabilidade sanitária e evitando a culpabilização; estabelecer uma relação horizontal, contínua e solidária com as $E q A B$, visando à troca de saberes e práticas entre equipes e apoiadores. (G10).

No entanto, é preciso estar atento, pois a construção de sujeitos autônomos é uma conquista processual, dinâmica, que pode ser disparada pelo apoio a partir do momento em que são criados espaços para se questionar todo o conjunto de leis, normas, padrões e valores que compõem as instituições. Esse movimento, apesar de indispensável para a construção de instituições democráticas e mudanças das pessoas que nela trabalham, é permeado por conflitos, interesses, desejos e problemas bastante diversos.

Ao mesmo tempo que identificam e analisam seus problemas, os coletivos necessitam do apoio para aumentar a capacidade de análise de forma a potencializar a elaboração de críticas reflexivas sobre suas práticas, suas relações com e na instituição, que, desse modo, potencializem mudanças necessárias para a produção de mais e melhor saúde.

Nesse sentido, é fundamental que o profissional que exerça a função apoio às equipes, em qualquer configuração de apoio existente no município, seja qualificado e também apoiado para operar com as tecnologias e ferramentas do apoio proposto por Campos (2000), apreendendo da realidade apoiada os saberes, os poderes e os afetos envolvidos, necessários aos processos de mudança.

\section{Dimensão pedagógica}

Nessa dimensão, partiu-se do entendimento de que a função apoio, além de apostar na transformação em ato de sujeitos e instituições, tem também por finalidade contribuir para a formação dos sujeitos.

Nesse sentido, o apoio alia-se à EPS por se constituir em uma estratégia fundamental para as transformações do trabalho no setor saúde, transformando-o em espaço privilegiado para a "crítica reflexiva, propositiva, compromissada e tecnicamente competente" (CECCIM, 2005, P. 976). No entanto, ainda para esse autor, faz-se necessário descentralizar e disseminar a capacidade pedagógica entre trabalhadores, gestores de ações e serviços de saúde, órgãos formadores e com o controle social do SUS.

A preocupação com os 'processos de formação e qualificação de profissionais e gestores' por parte de algumas gestões (G1, G3, G14, G16, G18, G19 e G21) foi explicitada em suas diretrizes: "Integração das ações de 'educação permanente' alicerçadas no cotidiano dos trabalhadores" (G18).

Formação e qualificação das referências técnicas para assumirem a função específica do Al [apoio institucional]; investir na formação/qualificação de todos os gestores da rede para atuarem na perspectiva da função apoio, desenvolvendo suas funções de gerência sob concepção e método do apoio institucional. (G19).

Campos (2000) defende que nos processos de gestão, principalmente os fundamentados na cogestão, produzem-se, além dos efeitos políticos e administrativos, também os pedagógicos e subjetivos. Os espaços coletivos, portanto, cumpririam uma função analítica e pedagógica, conciliando o cumprimento de seus objetivos na produção da saúde de assegurar a sobrevivência da instituição e a constituição de sujeitos. Nessa percepção, esses espaços constituir-se-iam um setting privilegiado para a EPS.

Observa-se nas diretrizes expostas uma preocupação com a produção de novos arranjos institucionais, novos pactos com o objetivo de ressignificar o cotidiano a partir da análise e da problematização da realidade singular vivenciada pelos atores no cenário de práticas. A partir dessa realidade proposta por alguns gestores das capitais brasileiras, construir-se-iam as demandas para a qualificação de gestores e trabalhadores das EqSF.

Contudo, embora explicitado em políticas 
e documentos institucionais o estímulo a uma gestão democrática, observa-se, por exemplo, que o envolvimento de usuários não é mencionado por nenhum gestor nessas ações. Tal fato é também percebido nas experiências de EPS identificadas no ano de 2009, quando se evidenciaram a ausência do usuário e a ênfase dada de forma majoritária na relação gestão-trabalhadores (FEUERWERKER, 2014).

Como afirmam Ceccim e Ferla (2009), a EPS é, antes de tudo, a expressão de uma opção político-pedagógica e não um processo didático pedagógico. Desse modo, no momento em que a EPS é tomada pelos gestores como diretriz institucional, pode estar implícito nessa opção um compromisso com o redirecionamento do modelo de atenção, da organização dos serviços e de processos de trabalho.

Identifica-se que, embora G16 e G21 tenham formulado suas diretrizes institucionais de forma 'concisa' com relação aos processos formativos, é visível que a maioria dos gestores que se manifestaram a esse respeito concorda que a qualificação dos gerentes e trabalhadores da $\mathrm{AB}$ seja estruturada na EPS de modo a contemplar as necessidades de aprendizado identificadas pelas equipes e os desafios à qualificação do processo de trabalho.
Desse modo, acredita-se que só se pode pensar em processos pedagógicos transformadores dos sujeitos e da realidade se tais processos forem significativos, que se desloquem saberes, poderes, desejos, interesses individuais ou corporativos em prol de um acúmulo democrático em que gestores, trabalhadores e usuários sejam sujeitos em potencial.

\section{'Entre a intenção e o gesto': os cro- nogramas para as diretrizes do apoio institucional}

Observaram-se três situações referentes aos cronogramas apresentados pelas gestões das capitais brasileiras: 1) gestões que não formularam ou não informaram cronogramas para suas diretrizes foram maioria (G3, G4, G6, G8, G13, G16, G17, G18, G21 e G22); 2) gestões que preencheram o formulário com descrição vaga ou, ainda, expressando incompatibilidade com as diretrizes propostas foram os casos de G1, G5, G7, G12, G14, G15, G19 e G20; e, por fim, G2, G9, G10 e G11, gestões cujos conteúdos dos cronogramas estabeleceram maior coerência com as diretrizes, embora tenham sido descritos de forma abrangente (quadro 1).

\begin{tabular}{|c|c|}
\hline $\begin{array}{c}\text { Gestão } \\
\text { da Atenção Básica }\end{array}$ & $\begin{array}{l}\text { CRONOGRAMA DE IMPLANTAÇÃO DAS DIRETRIZES PARA O APOIO INSTITUCIO- } \\
\text { NAL NO MUNICÍPIO }\end{array}$ \\
\hline G1 & Implantado, com cronograma mensal sistemático. \\
\hline G2 & $\begin{array}{l}\text { Diretriz } 1 \text { - Implementar a atenção integral à saúde até dezembro de 2013. Diretriz } 2 \\
\text { - Fortalecer a vigilância à saúde e o ambiente até dezembro de 2013. Diretriz } 3 \text { - Desen- } \\
\text { volver a gestão participativa no SUS [local] até dezembro de } 2013 .\end{array}$ \\
\hline G3 & Não informou. \\
\hline G4 & Ainda não está previsto. \\
\hline G5 & $\begin{array}{l}\text { Este grupo de apoiadores está formado desde a criação dos distritos sanitários. Os } \\
\text { apoiadores locais têm reuniões quinzenais com as equipes, e os apoiadores distritais } \\
\text { têm reuniões semanais com os apoiadores das equipes, e os apoiadores do centro de } \\
\text { informação em saúde são contactados conforme as necessidades das equipes da APS. }\end{array}$ \\
\hline G6 & Não informou. \\
\hline G7 & $\begin{array}{l}\text { Meta da inserção de } 15 \text { Nasf até o final de } 2013 \text { - conforme PMS, o cronograma se dará } \\
\text { conforme o número de equipes por apoiador. }\end{array}$ \\
\hline
\end{tabular}




\begin{tabular}{|c|c|}
\hline $\begin{array}{c}\text { Gestão } \\
\text { da Atenção Básica }\end{array}$ & $\begin{array}{l}\text { CRONOGRAMA DE IMPLANTAÇÃO DAS DIRETRIZES PARA O APOIO INSTITUCIO- } \\
\text { NAL NO MUNICÍPIO }\end{array}$ \\
\hline G8 & Não informou. \\
\hline G9 & $\begin{array}{l}\text { A Oficina para construção do método de trabalho da equipe de apoiadores será realiza- } \\
\text { da no dia } 23 \text { de agosto de 2012; a partir da oficina, será elaborado cronograma de visitas } \\
\text { às EqSF e aos Pacs. }\end{array}$ \\
\hline G10 & $\begin{array}{l}\text { Definição das unidades a receberem apoio institucional - junho de 2012. Definição da } \\
\text { Equipe de Apoio Institucional (EAI) - junho de 2012. Educação permanente - mensal. } \\
\text { Reuniões setoriais nos Distritos de Saúde para discussão e encaminhamentos das } \\
\text { situações encontradas - mensais; Visitas do apoio institucional às unidades de saúde - } \\
\text { mensal. }\end{array}$ \\
\hline G11 & $\begin{array}{l}\text { Outubro - contratualização das equipes; março - divulgação para as equipes do pro- } \\
\text { cesso; informação do acompanhamento ao Conselho Municipal de Saúde (CMS); abril } \\
\text { a junho - autoavaliação e avaliação externa; agosto - avaliação interna dos indicadores; } \\
\text { setembro a dezembro - período para } 2^{\circ} \text { avaliação interna dos indicadores. }\end{array}$ \\
\hline G12 & Avaliação de três equipes - semanal. \\
\hline G13 & Não informou. \\
\hline G14 & Novembro de 2011. \\
\hline G15 & Início de 2005. \\
\hline G16 & Não informou. \\
\hline G17 & Não informou. \\
\hline G18 & Não informou. \\
\hline G19 & $\begin{array}{l}\text { Desde 2010, o Al segue essas diretrizes operacionais. O Al de cada UBS busca articular } \\
\text { os projetos estratégicos de reorganização da atenção e da gestão, em estreita parceria } \\
\text { com os técnicos envolvidos na educação permanente (incluindo oficinas de qualificação } \\
\text { na APS), em gestão clínica, vários âmbitos do matriciamento (inclui o Nasf) e agendas } \\
\text { programáticas da UBS, buscando direcionar os diversos tipos de ações e metas para o } \\
\text { campo de abrangência dos contratos internos de gestão. }\end{array}$ \\
\hline G20 & $\begin{array}{l}\text { Esta atividade é realizada de forma contínua [na instituição A] junto aos serviços, res- } \\
\text { peitando as reuniões de equipes e os colegiados gestores nos serviços de saúde que } \\
\text { têm apoiador institucional. }\end{array}$ \\
\hline G21 & Não informou. \\
\hline G22 & Não informou. \\
\hline
\end{tabular}

Fonte: Elaboração própria, a partir do banco do módulo IV PMAQ.

Os dados apontam fragilidade ou mesmo 'descaso' dos gestores da $\mathrm{AB}$ na construção de modelos de gestão alicerçados em uma democracia institucional. Questionou-se, também, sobre a alimentação desses dados no formulário virtual, especialmente, com relação a quem, de que forma e com qual concepção de apoio os dados foram preenchidos.

Na perspectiva de construção compartilhada de processos e resultados, é fundamental a existência de contratos em que esteja explícita a definição de tarefas e a divisão de responsabilidades. Para Rodrigues (2011), o cronograma é uma ferramenta útil na gestão de projetos para monitorar o andamento das atividades relacionadas ao tempo, de modo que se possa garantir a finalização de um projeto numa data planejada e controlada e/ ou estimada.

O agir dos coletivos na produção de valores de uso e de sua própria reprodução, na visão de Campos (2000, P. 141), torna-se fundamental para a 
[...] formação de um campo de compromissos, de projetos e de contratos pactuados, que permitiriam a gestão dessa miríade de vetores de forças que atravessa qualquer coletivo.

Observou-se que, embora possa se criar expectativa de que as gestões da $\mathrm{AB}$ das capitais brasileiras, devido às condições de estrutura física e organizativa e de pessoal, teriam melhores e maiores condições de gerir os processos para a institucionalização do apoiocomrelação a outros municípios, parece que essa não é uma realidade predominante. Desse modo, torna-se evidente que as gestões municipais precisam, também, ser apoiadas na condução desses processos.

\section{Conclusão}

No instante em que se tomou como objeto desta investigação a oferta do apoio institucional pelas gestões das capitais brasileiras, buscou-se identificar nesse universo os avanços e recuos, contradições e possibilidades da função apoio enquanto estratégia que tem por finalidade contribuir para a democracia institucional e a autonomia dos sujeitos.
Embora se crie certa expectativa de que as gestões da $\mathrm{AB}$ das capitais brasileiras (por sua condição de estrutura física e organizativa e de pessoal) teriam melhores e maiores condições de gerir os processos para a institucionalização do apoio em relação a outros municípios, parece que essa não é uma realidade predominante. Desse modo, torna-se evidente que as gestões municipais precisam, também, ser apoiadas na condução desses processos. Por isso, ressalta-se a importância de fortalecer o apoio integrado, que busca, a partir da ênfase na dimensão formativa, um modo de participar da relação com os outros entes federados que ultrapasse o aspecto normativo e o da indução financeira.

Mesmo que limitada ao recorte de uma realidade, tem-se a convicção da importância que é para o investigador trilhar os caminhos de incertezas e de descobertas a cada aproximação que é feita na realidade investigada. Desse modo, as aproximações aqui realizadas são delineadas pela produção de um conhecimento contextualizado, histórico e social, a partir do aporte teórico aqui adotado, sendo, portanto, destituído de certezas e que, longe de estar acabado, necessitará de constantes buscas.

\section{Referências}

BRASIL. Ministério da Saúde. Secretaria de Atenção à Saúde. Departamento de Atenção Básica. Autoavaliação para a Melhoria do Acesso e da Qualidade da Atenção Básica: AMAQ. Brasília, DF, 2012a.

. Ministério da Saúde. Secretaria de Atenção à

Saúde. Departamento de Atenção Básica. Programa

Nacional de Melhoria do Acesso e da Qualidade da Atenção Básica (PMAQ): manual instrutivo/Ministério da Saúde. Brasília, DF, 2012b.

BARDIN, L. Análise de conteúdo. Lisboa: Edições 70, 2011.
BAREMBLITT, G. Compêndio de análise institucional e outras correntes: teoria e prática. 5. ed. Belo Horizonte: Instituto Félix Guattari, 2002.

CAMPOS, G. W. S. O anti-Taylor: sobre a invenção de um método para co-governar instituições de saúde produzindo liberdade e compromisso. Cad. Saúde Pública, Rio de Janeiro, v. 14, n. 4, p. 863-870, out. 1998. Apoio matricial e institucional em Saúde: entrevista com Gastão Wagner de Sousa Campos. Interface, Botucatu, v. 18, supl. 1, p. 1145-1150, dez. 2014. Entrevistador: Liane Beatriz Righi. Disponível 
em: <http://www.scielo.br/scielo.php?script=sci arttext\&pid=S1414-32832014000501145\&lng=en\&nrm =iso $>$. Acesso em: 28 maio 2015.

Um método para análise e co-gestão de coletivos. 3. ed. São Paulo: Hucitec, 2000.

Paideia y gestión: un ensayo sobre el soporte paideia en el trabajo en salud. Salud colectiva, Lanús, v. 1, n. 1, abr. 2005.

Saúde Paidéia. São Paulo: Hucitec, 2003.

CAMPOS, G. W. S.; CUNHA, G. T.; FIGUEIREDO,

M. D. Práxis e formação Paidéia: apoio e cogestão em saúde. São Paulo: Hucitec, 2013.

CECCIM, R. B. Educação permanente em saúde: descentralização e disseminação de capacidade pedagógica na saúde. Ciênc. saúde coletiva, Rio de Janeiro, v. 10, n. 4, p. 975-986, dez. 2005.

CECCIM, R. B.; FERLA, A. A. Educação permanente em saúde. In: PEREIRA, I. B.; LIMA, J. C. F. Dicionário da educação profissional em saúde. 2. ed. rev. ampl. Rio de Janeiro: EPSJV, 2009, p. 162-178.

CONTANDRIOPOULOS, A. P. Avaliando a institucionalização da avaliação. Ciênc. saúde colet., Rio de Janeiro, v. 11, n. 3, p. 705-711, jul./set. 2006.

FEUERWERKER, L. C. M. (Org.). Micropolítica e saúde: produção do cuidado, gestão e formação. Porto Alegre: Rede UNIDA, 2014.

FOCAULT, M. Microfísica do poder. 27. ed. São Paulo: Graal, 2009.

LOURAU, R. Objeto e método da análise institucional.
In: ALTOÉ, S. (Org.). René Lourau: analista institucional em tempo integral. São Paulo: Hucitec, 2004, p. 66-86.

ORGANIZAÇÃO MUNDIAL DE SAÚDE (OMS). Relatório mundial de saúde 2008: cuidados de saúde primários - agora mais que nunca. Lisboa: Organização Mundial da Saúde e Alto Comissariado para a Saúde, 2008. Disponível em: <http://www.pmf. sc.gov.br/arquivos/arquivos/pdf/31_03_2010_9.22.37.7 Ofbb6ffd32f6598e4de044a8feeacdc.pdf >. Acesso em: 23 abr. 2014

PAULON, S. M., PASCHE, D. F.; RIGHI, L. B. Função apoio: da mudança institucional à institucionalização da mudança. Interface, Botucatu, São Paulo, v. 18, supl. 1, p. 809-820, dez. 2014.

PEREIRA JUNIOR, N.; CAMPOS, G. W. S. O apoio institucional no Sistema Único de Saúde (SUS): os dilemas da integração interfederativa e da cogestão. Interface, Botucatu, São Paulo, v. 18, supl. 1, p. 895-908, dez. 2014.

RODRIGUES, E. Gestão de projetos na prática: blog. 2011. Disponível em: <http://www.elirodrigues. com/2011/01/31/como-fazer-um-cronograma/> Acesso em: 10 dez. 2014.

SILVEIRA, R. A. Michel Foucault: poder e análise das organizações. Rio de Janeiro: FGV, 2005.

STARFIELD, B. Atenção Primária: equilíbrio entre necessidades de saúde, serviços e tecnologia. Brasília, DF: Unesco/Ministério da Saúde, 2002.

Recebido para publicação em junho de 2015

Versão final em outubro de 2015

Conflito de interesses: inexistente

Suporte financeiro: não houve 